\title{
Performance of Cordyceps militaris Mutant Regarding Anti-cancer Agent Cordycepin Production in Subme rged Culture Obtained by Ion Beam Irradiation
}

\author{
S.K. Das ${ }^{1 *}$, M. Masu da ${ }^{1}$, M. Hatashita ${ }^{2}$, A. Sakurai ${ }^{1}$ and M. Sakakibara ${ }^{1}$ \\ ${ }^{1}$ Department of Applied Chemistryand Biotechnology, GraduateSchool of Engineering, University of Fukui, \\ Fukui 910-8507, Japan \\ ${ }^{2}$ Research and Development Department, The Wakasa-wan Energy Research Center, Tsuruga 914-0192, Japan \\ *E-mail: skdas76@yahoo.com
}

Received: 26.09.2009, Accepted: 03.122009

\begin{abstract}
Performance of Cordyceps militaris mutant obtained by high-energy ion beam irradiation regarding anti-cancer agent cordycepin production in submerged culture was investigated. It was established that the mutant renders a higher production performance in surface liquid culture, needs to observe its performance in submerged culture. Two kinds of media were used for submerged culture comprising a basal medium and the optimized media for $C$. militaris mutant and control (wild strain) each. HPLC analy sis for cordycepin concentration, mutarotase GOD (glucose oxidase) method using Glucose CII test for glucose concentration, $\mathrm{pH}$ meter for $\mathrm{pH}$ were measured. Analysis showed that the cordycepin production of mutant in submerged culture using basal medium was 2.82 times (181.77\%) higher that of the control; whereas, in optimized media, the production of control was 9.06 times (80625\%) higher than that of the mutant. In contrast, the cordycepin productions of this mutant in submerged culture were suppressed to about $80 \%$ and $3 \%$ relative to the surface liquid culture; whereas, those controls were about $30 \%$ and $80 \%$ using basal and optimized media, respectively. Glucose consumption was faster in all cases of the control in both basal and optimized media with a higher mycelial growth, and interestingly, it was extremely slow in case of mutant in optimized medium. The $\mathrm{pH}$ analysis showed that as the production was increasing, the $\mathrm{pH}$ value also increasing towards the neutral $(\mathrm{pH}=7)$ in all the cases of mutant and control, except in case of mutant using optimized mediumin which the $\mathrm{pH}$ value remained more or less static accompanied by a lower production. These results suggested that the prospective mutant had a poor performance in submerged culture using optimized media, but had a better performance in basal medium, although the production in basal medium is too low to be taken into consideration as a commercial point of view. Stress furnished by shaking may be one of the major explainable causes of decreased production here. It my also be assumed that with a lower concentrations of C and $\mathrm{N}$ sources, this mutant is better tolerable to shear stress. Therefore, it is suggested to use surface liquid culture rather than the submerged one to attain the highest production performance to be used for industrial uses.
\end{abstract}

Key words: Production performance, Cordyceps militaris mutant, submerged culture, anticancer agent production

\section{Introduction}

Use of medicinal mushrooms, such as

Cordyceps species, especially Cordyceps 
S.K. Das, M. Masuda, M. Hatashita, A. Sakurai and M. Sakakibara / Our Nature (2009) 7: $1-9$

militaris (an entomo-pathogenic fungus), has been extensively studied in biotechnological processes for producing anti-cancer agent cordycepin and, due to its various physiological activities; it is now used for multiple medicinal purposes (Song et al., 1988; Mizuno, 1999). Cordyceps militaris is one of the best harbors of a unique nucleoside analogue cordycepin $\left(3^{\prime}-\right.$ deoxyadenosine), which has a broad spectrum of biological properties and, there are many reports concerning its isolation (Cunningham et al., 1951; Jiang and Sun, 1999). The natural C. militaris is rare and expensive in the local market. Moreover, as this fungus requires specific hosts and strict growth environments, it is very scarce in nat ure, and therefore, cordycepin production from Cordyceps militaris on a large scale is a significant issue. Although it can be also chemically synthesized, the yield is not high enough. In addition, it needs a complicated process and significantly long reaction time and, a large volume of organic solvents that are harmful substances to the environment are also discharged (Hansske and Robins, 1985; Aman et al., 2000).

In our previous experiments, a new mutant of the Cordyceps militaris was obtained using ion beam irradiation technology (Das et al., 2008). In addition, the optimized glucose concentrations were $86.2 \mathrm{~g} \mathrm{l}^{-1}$ and $62.6 \mathrm{~g} \mathrm{l}^{-1}$ as the carbon source; the yeast extract concentrations were $93.8 \mathrm{~g}$ $\mathrm{I}^{-1}$ and $72.5 \mathrm{~g} \mathrm{l}^{-1}$ as the nitrogen source; and the cordycepin productions were $6.84 \mathrm{~g} \mathrm{l}^{-1}$ and $2.45 \mathrm{~g} \mathrm{l}^{-1}$, successfully obtained in our previous study for the mutant and control, respectively. This is the highest cordycepin production reported until today. In an elaborative study to establish this mutant as a sustainable one, it needs to observe its performance in submerged culture as many researchers are using this technique for the production of cordycepin (Mao and Zhong, 2004; Mao et al., 2005; Mao and Zhong, 2006; Masuda et al., 2006, 2007; Shih et al., 2007). From this standpoint, it was of a great interest to verify the performance of this C. militaris mutant in submerged culture using basal and optimized media in contrast to surface liquid culture in more detail.

\section{Mate rials and methods \\ Microorganism and culture}

Cordyceps militaris NBRC 9787, a wild microbial strain (control) from National Institute of Technology and Evaluation (Chiba, Japan), and a mutant (G81-3) of the above mentioned fungus obtained by a highenergy ion beam irradiation as a novel approach (Das et al., 2008), were used in the present experiments. Both the mutant and control were stored at $5^{\circ} \mathrm{C}$.

The active PDA (Nissui Pharmaceutical Co. Ltd., Japan) slant from the stock culture for this mutant and control was prepared by culturing for 8 days at $25^{\circ} \mathrm{C}$, and then the seed culture transferred from the active slant was grown on a $9 \mathrm{~cm}$ PDA plate for 20 days in case of mutant and, 13 days for control at $25^{\circ} \mathrm{C}$. The inoculant was prepared by punching out $1 \mathrm{~cm}$ of the PDA plate culture using a sterilized cylindrical cutter. The submerged culture was started by inoculating the inoculant (seed disk) into a $500 \mathrm{ml}$ Erlenmeyer flask (no buffled), and the working volume of the medium was 100 $\mathrm{ml}$ for each flask. The prepared flaks were incubated at $25 \pm 1^{\circ} \mathrm{C}$ on a rotary shaker incubator at $50 \mathrm{rpm}$ until the glucose concentration becomes zero. A $0.75 \mathrm{ml}$ portion of the medium was mainly sampled 
S.K. Das, M. Masuda, M. Hatashita, A. Sakurai and M. Sakakibara / Our Nature (2009) 7: $1-9$

at 3 day intervals and filtered through a 0.45 $\mu \mathrm{m}$ membrane filter in order to remove the suspended mycelia. The filtrate was analyzed for cordycepin, glucose and $\mathrm{pH}$. All experiments were carried out at least in duplicate, and the results were then averaged. The composition of the basal medium for both the mutant and control was as described by Das et al. (2008). The optimized media used for mutant and control each in this experiment was as shown in Table 1.

\section{Analytical procedures}

The cordycepin concentration was determined by HPLC equipped with a UV detect or (LC-9A system, Shimadzu Corp., Japan) and a reverse phase column (T SKgel ODS-80Ts, Tosoh Corp., Japan). The mobile phase consisted of methanol and $0.1 \%$ phosphoric acid $\left(2 / 98, \mathrm{v} \mathrm{v}^{-1}\right)$. The flow rate was $1.0 \mathrm{~m} \mathrm{l}^{-\mathrm{min}}$, and the column temperature was $40^{\circ} \mathrm{C}$. The chromatogram was monitored by the UV absorbance at 260 $\mathrm{nm}$. The cordycepin concentration shown in this experiment was re-estimated by considering the condensation of the medium in the culture bottle due to vaporization.

The glucose concentration was analyzed by the mutarotase GOD (glucose oxidase) method using the Glucose CII test Wako (Wako Pure Chemical Industries, Ltd., Japan). The $\mathrm{pH}$ of the collected samples was measured by a $\mathrm{pH}$ meter.

\section{Resul ts and discussion Cordycepin production in basal medium}

Analysis showed that the highest cordycepin productions in submerged culture using basal medium were 0.572 and $0.203 \mathrm{~g} \mathrm{l}^{-1}$ for mutant and control, respectively, i.e. the production of mutant was 2.82 times
$(181.77 \%)$ higher that of the control (Figures 1-2).

In contrast, the cordycepin productions in submerged culture were suppressed to about $80 \%$ and $30 \%$ relative to the surface liquid culture using basal medium for the mut ant and control, respectively.

Regarding glucose consumption, it was revealed that the glucose consumption in case of control was a little faster than that of mut ant using basal medium with a very little higher mycelial growth (Figures 1-2).

\section{Cordycepin production in optimized}

Using the optimized media for submerged culture it was revealed that the highest cordycepin productions were 0.240 and $2.175 \mathrm{~g} \mathrm{l}^{-1}$ for the mutant and control, respectively. It means that the production by the control was 9.06 times (806.25\%) higher than that of the mutant (Figures 3-4).

In contrast, the cordycepin productions in submerged culture were suppressed to about $3 \%$ and $80 \%$ relative to the surface liquid culture using optimized media for the mut ant and control, respectively.

Regarding glucose consumption, it was revealed that the glucose consumption in case of control was faster than that of mutant using the optimized media with a higher mycelial growth (Figures 3-4). In fact, the glucose consumption in case of mutant was extremely slow.

These results suggested that the prospective mut ant had a poor performance in submerged culture using optimized media, but had a better performance in basal medium, although the production in basal medium is too low to be taken into consideration as a commercial point of view. Stress furnished by shaking may be one of the major explainable causes of 
S.K. Das, M. Masuda, M. Hatashita, A. Sakurai and M. Sakakibara / Our Nature (2009) 7: $1-9$

Table 1. Composition of optimized media for mutant and control

\begin{tabular}{|c|c|c|}
\hline \multirow{2}{*}{ Components } & \multicolumn{2}{|c|}{ Concentration $\left(\mathrm{g} \mathrm{l}^{-1}\right)$} \\
\hline & Mutant & Control \\
\hline \multicolumn{3}{|l|}{ Nitrogen sources } \\
\hline Yeast extract & 93.8 & 72.562 .6 \\
\hline \multicolumn{3}{|l|}{ Carbon source } \\
\hline Glucose & 86.2 & \\
\hline \multicolumn{3}{|c|}{ Others (diluted to $110^{-1}$ concentration of Vogel's medium) } \\
\hline $\mathrm{NaOC}(\mathrm{COOH})\left(\mathrm{CH}_{2} \mathrm{COONa}\right)_{2} \cdot 2 \mathrm{H}_{2} \mathrm{O}$ & 0.28 & \\
\hline $\mathrm{KH}_{2} \mathrm{PO}_{4}$ & 0.50 & \\
\hline $\mathrm{NH}_{4} \mathrm{NO}_{3}$ & 0.20 & \\
\hline $\mathrm{MgSO}_{4} \cdot 7 \mathrm{H}_{2} \mathrm{O}$ & 0.02 & \\
\hline $\mathrm{CaCl}_{2} \cdot 2 \mathrm{H}_{2} \mathrm{O}$ & 0.01 & \\
\hline Citric acid & $0.46 \times 10^{-3}$ & \\
\hline $\mathrm{ZnSO}_{4} \cdot 7 \mathrm{H}_{2} \mathrm{O}$ & $0.50 \times 10^{-3}$ & \\
\hline $\mathrm{Fe}\left(\mathrm{NH}_{4}\right)_{2}\left(\mathrm{SO}_{4}\right)_{2} \cdot 6 \mathrm{H}_{2} \mathrm{O}$ & $0.10 \times 10^{-3}$ & \\
\hline $\mathrm{CuSO}_{4} \cdot 5 \mathrm{H}_{2} \mathrm{O}$ & $0.025 \times 10^{-3}$ & \\
\hline $\mathrm{H}_{3} \mathrm{BO}_{3}$ & $5.0 \times 10^{-6}$ & \\
\hline $\mathrm{MnSO}_{4} \cdot(4-5) \mathrm{H}_{2} \mathrm{O}$ & $5.0 \times 10^{-6}$ & \\
\hline $\mathrm{Na}_{2} \mathrm{MoO}_{4} \cdot 2 \mathrm{H}_{2} \mathrm{O}$ & $5.0 \times 10^{-6}$ & \\
\hline
\end{tabular}

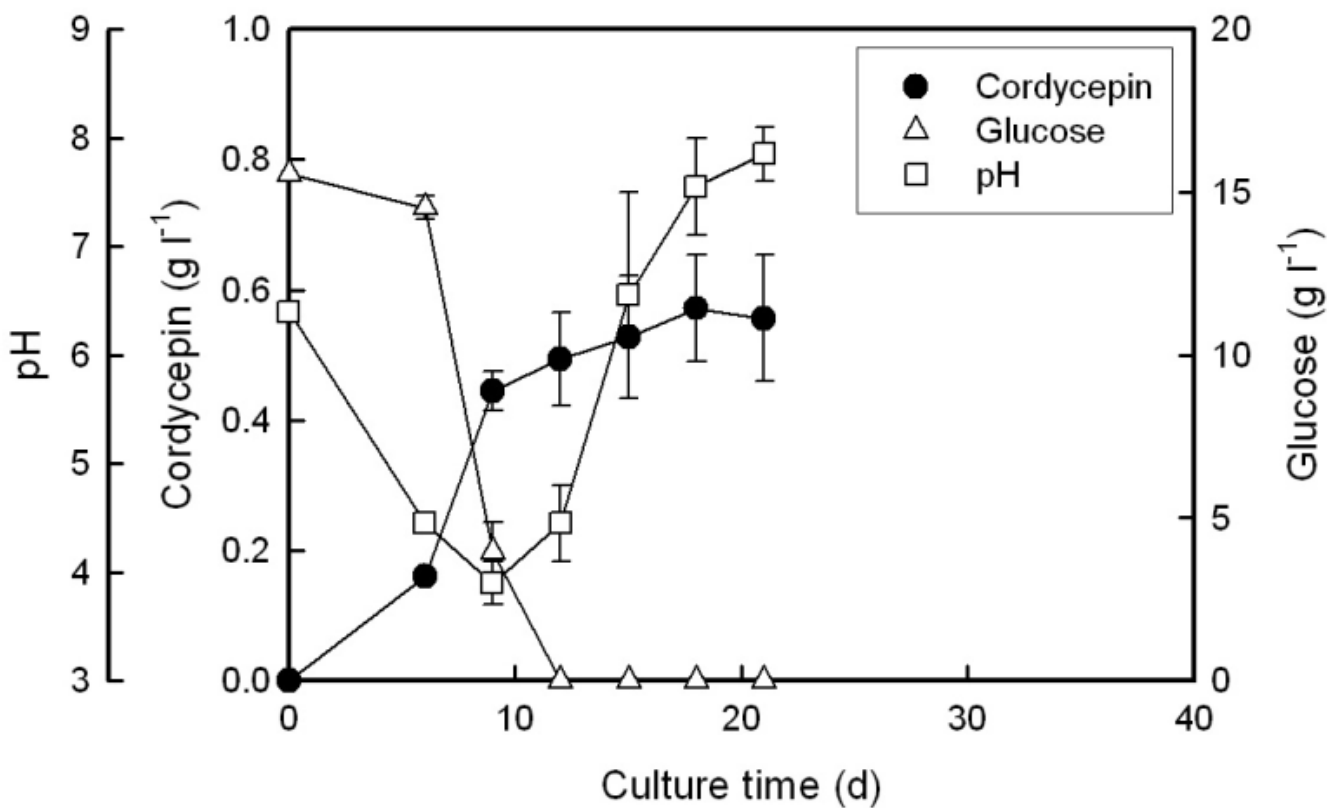

Figure 1. Time courses of submerged culture regarding glucose consumption, cordycepin production and $\mathrm{pH}$ using basal medium for mutant. 
S.K. Das, M. Masuda, M. Hatashita, A. Sakurai and M. Sakakibara / Our Nature (2009) 7:

$1-9$

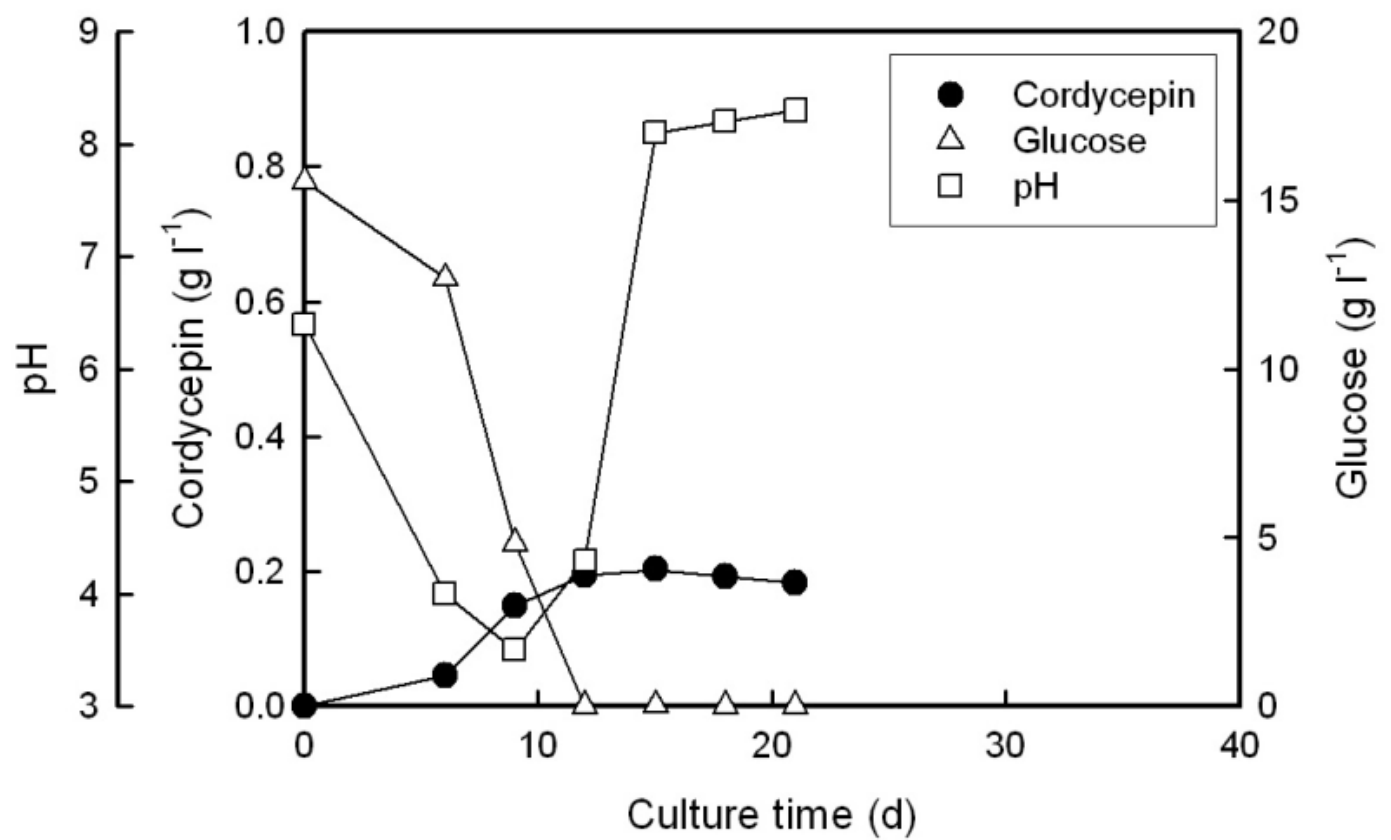

Figure 2. Time courses of submerged culture regarding glucose consumption, cordycepin production and $\mathrm{pH}$ using basal medium for control.

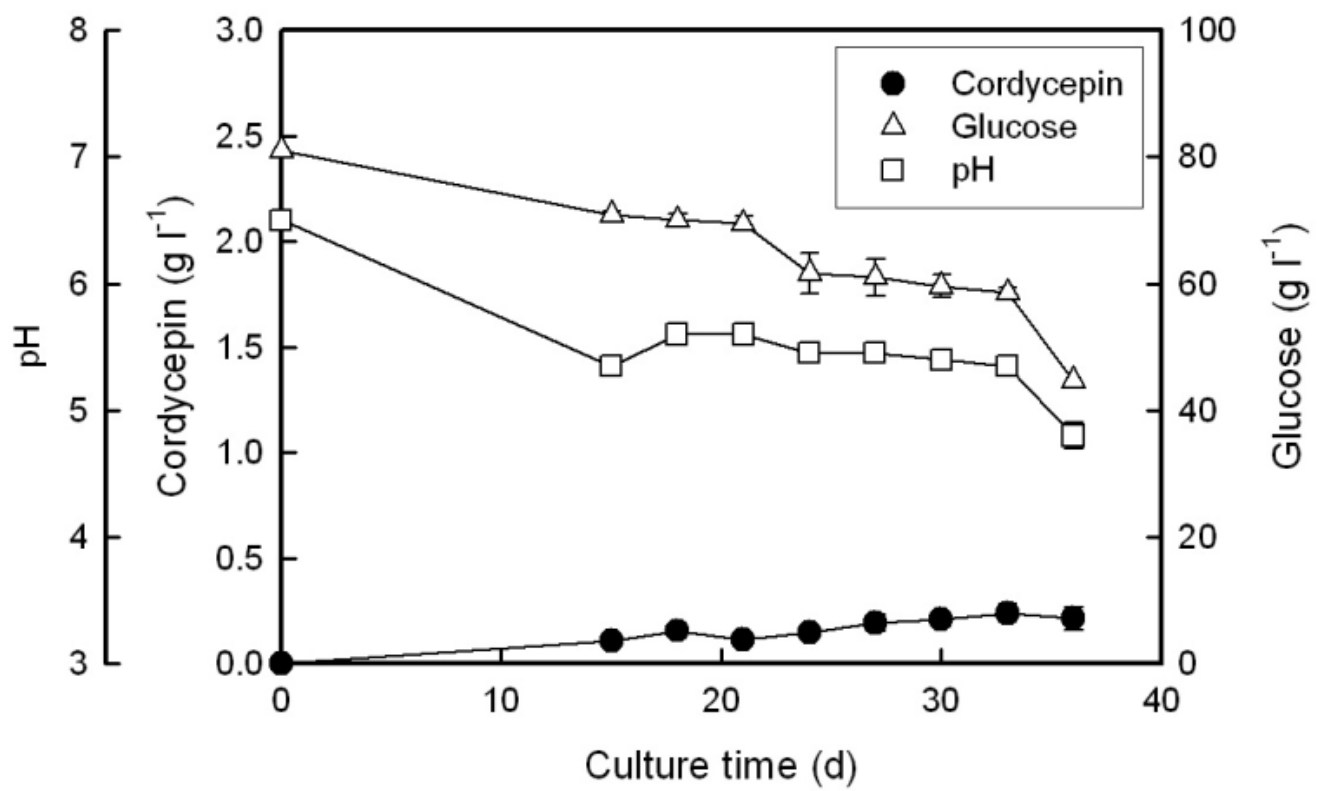

Figure 3. Time courses of submerged culture regarding glucose consumption, cordycepin production and $\mathrm{pH}$ using optimized medium for mutant. 
S.K. Das, M. Masuda, M. Hatashita, A. Sakurai and M. Sakakibara / Our Nature (2009) 7: $1-9$

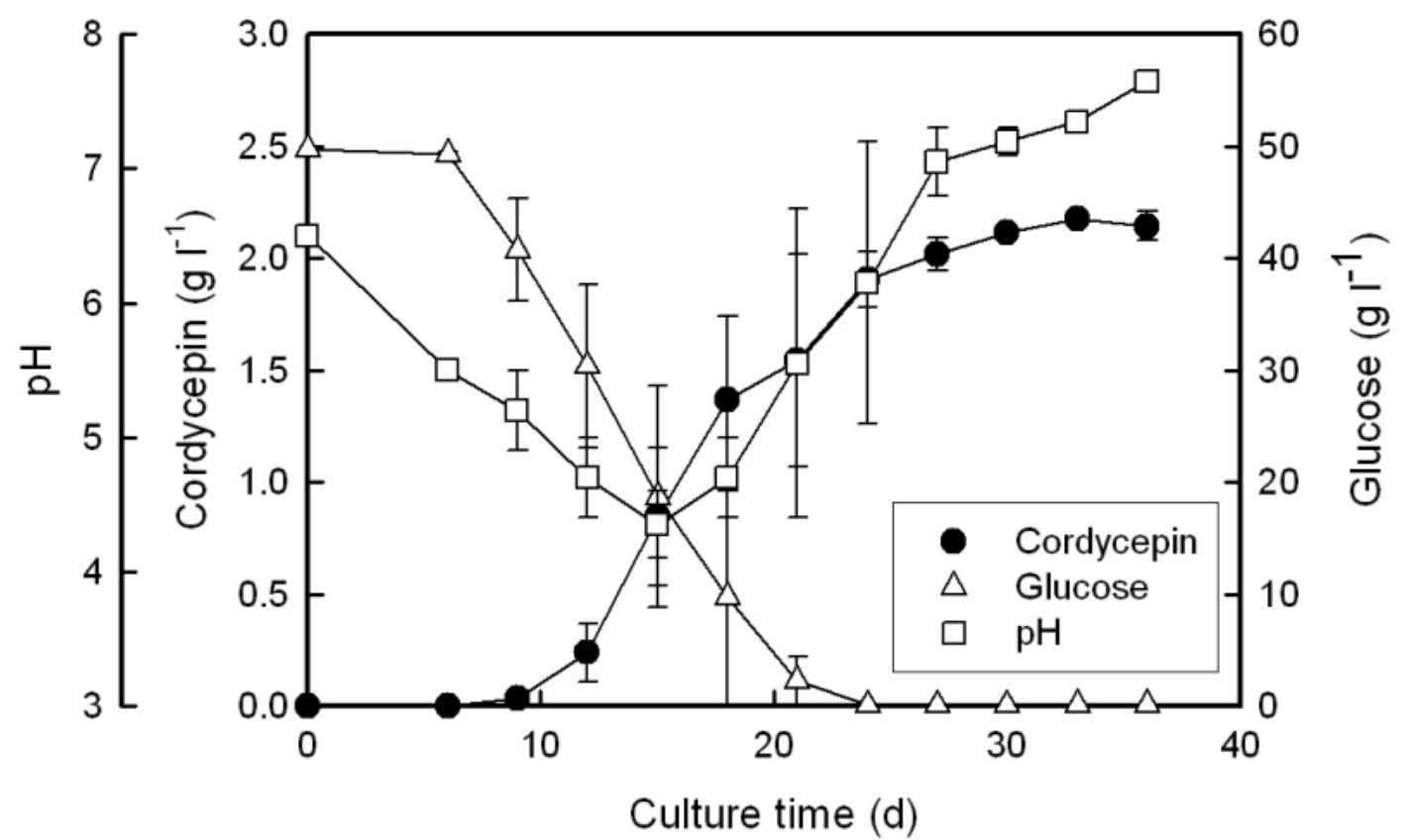

Figure 4. Time courses of submerged culture regarding glucose consumption, cordycepin production and $\mathrm{pH}$ using optimized medium for control.

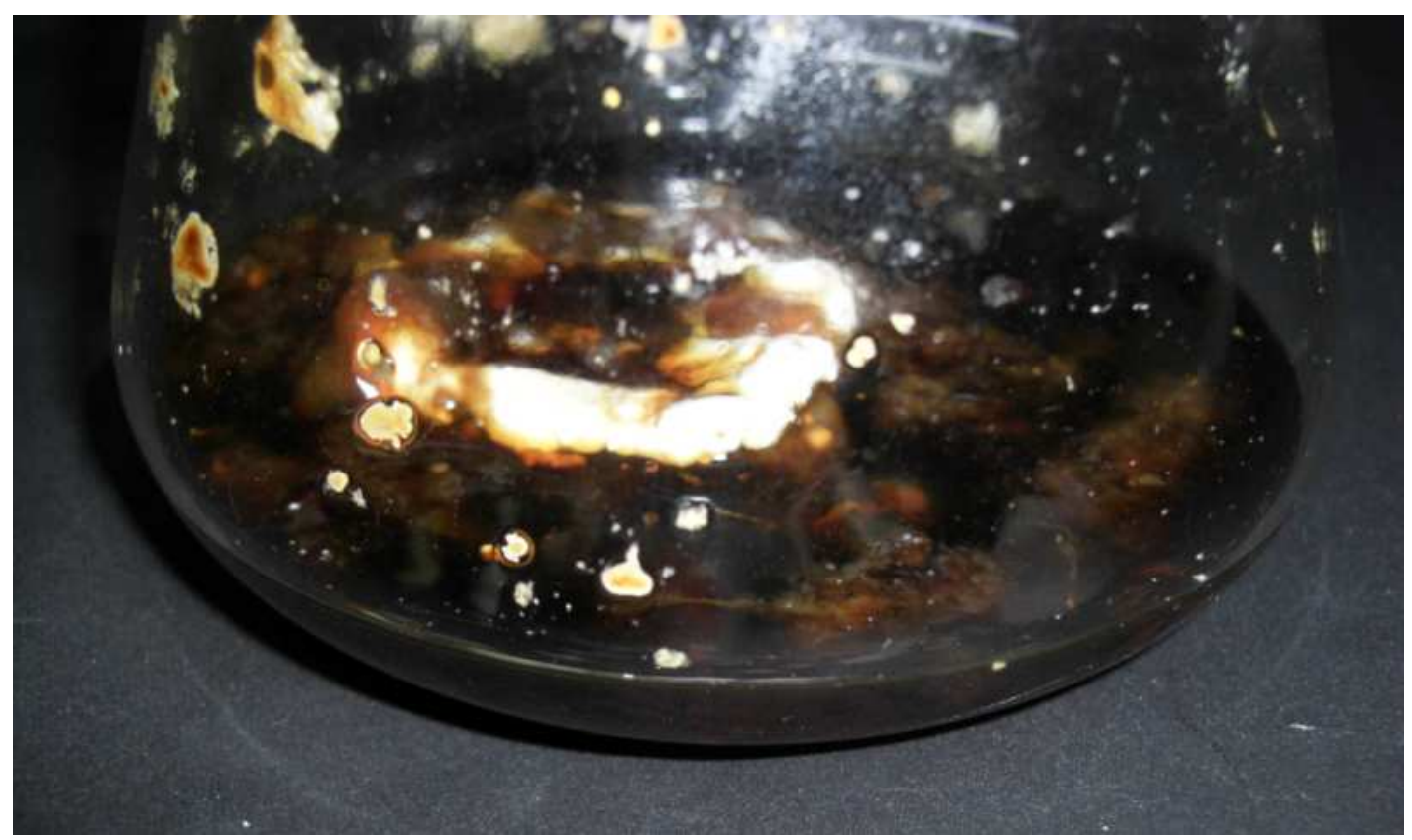

Figure 5a. Growth of mycelia of mutant. 
S.K. Das, M. Masuda, M. Hatashita, A. Sakurai and M. Sakakibara / Our Nature (2009) 7:

$1-9$

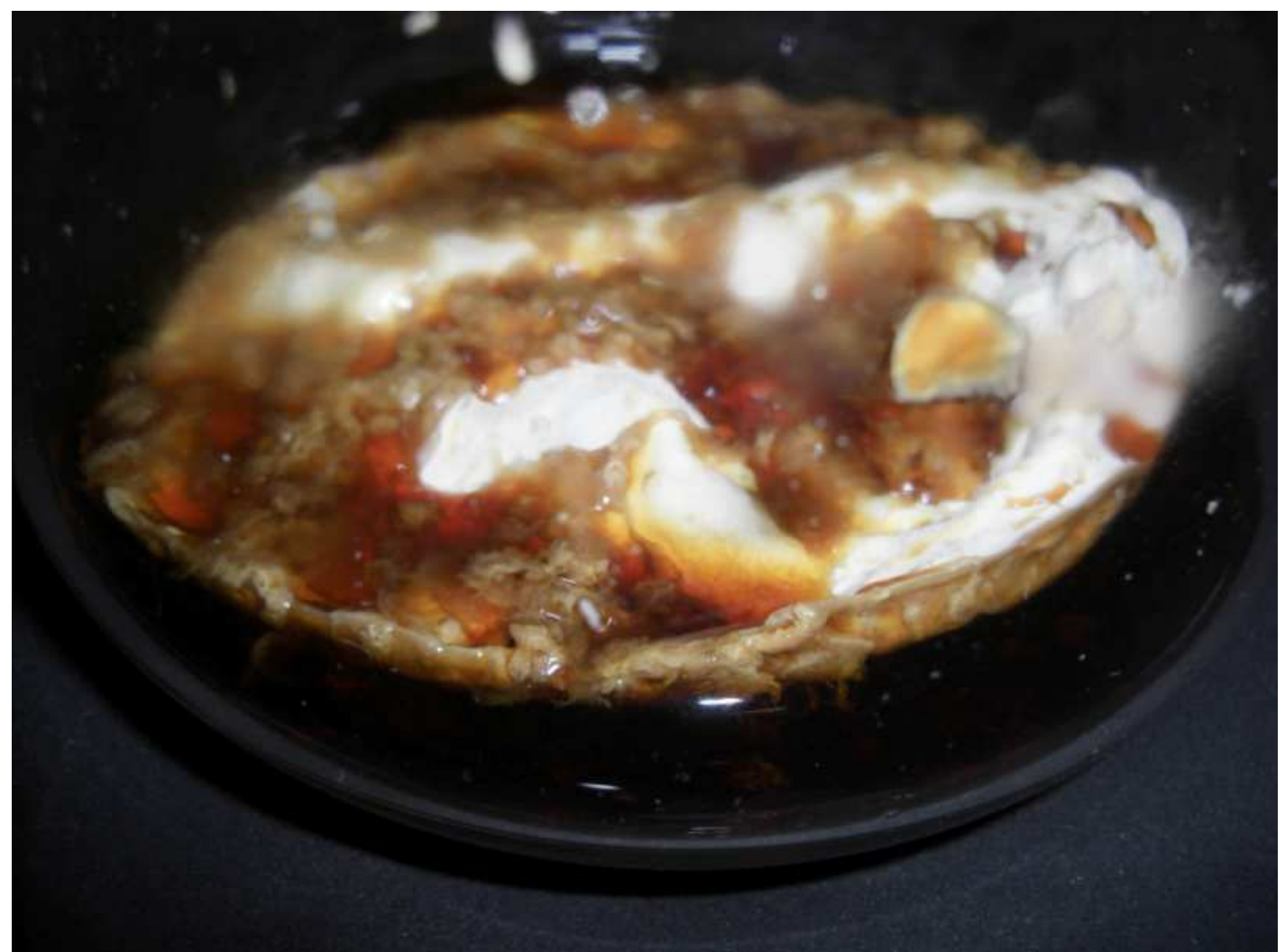

Figure 5b. Growth of mycelia of control using optimized media.

decreased production here. These results agreed entirely with the observations reported by Masuda et al. (2006). They mentioned that in case of submerged culture, the cordycepin production was suppressed to $110^{-1}$ (buffled Erlenmeyer flask) $\sim 13^{-1}$ (no buffled) relative to the surface liquid culture even if the other culture conditions were the same. It my also be assumed that with a lower concentrations of $\mathrm{C}$ and $\mathrm{N}$ sources, this mutant shows a better tolerance to shear stress.

From this experiment, it was revealed that a higher cordycepin production was accompanied by a faster glucose consumption rate indicating a positive correlation to each other.

\section{Mycelial growth}

In terms of mycelial growth, it was found that there was more or less similar mycelial growth of mutant and control in submerged culture using basal medium, but it was much higher for the control than that of the mutant while using optimized media (Figures 5a-b). There might have a positive relationship between mycelial growth and cordycepin production for both mut ant and control as a higher mycelial growth provided a higher cordycepin production. 
S.K. Das, M. Masuda, M. Hatashita, A. Sakurai and M. Sakakibara / Our Nature (2009) 7: $1-9$

\section{pH}

The $\mathrm{pH}$ analysis showed that as the production was increasing, the $\mathrm{pH}$ value also increasing towards the neutral $(\mathrm{pH}=7)$ in all cases of mutant and control, except in case of mutant using optimized medium in which the $\mathrm{pH}$ value remained more or less static accompanied by a lower production (Figures 1-4). It is also noteworthy that the $\mathrm{pH}$ value at the end of the culture is about neutral that is beneficial for the cordycepin separation and purification.

\section{Conclusion}

Submerged culture is a conventional culture technique usually used for fungus and mushroom cultures. Our present results showed that the cordycepin production of mutant using basal medium was 2.82 times higher that of the control; whereas, in optimized media, the production of control was 906 times higher than that of the mutant. On the other hand, the production of the anti-cancer agent cordycepin in surface liquid culture by this mutant was much higher than that of the control. Therefore, it is suggested that submerged culture is not as effective as the surface liquid culture regarding anti-cancer agent cordycepin production at a large scale. Therefore, it is suggested to use surface liquid culture rather than the submerged one to attain the highest production performance to be used for industrial uses. Although shaking stress might be responsible for decreased production, there might have another reasons remained unexplored, needs to be investigated.

\section{References}

Aman, S., D.J. Anderson, T.J. Connolly, A.J. Crittall and G. Ji 2000. From adenosine to $3^{\prime}-$ deoxyadenosine: development and scale up. Org. Process. Res. Dev. 4:601-605.

Cunningham, K.G., S.A. Hutchinson, W. Manson and F.S. Spring 1951. Cordycepin, a metabolic product from cultures of Cordyceps militaris (Linn.) Link. Part I. Isolation and characterization. J. Chem. Soc. 1: 2299-2300.

Das, S.K., M. Masuda, M. Hatashita, A. Sakurai and M. Sakakibara 2008. A new approach for improving cordycepin productivity in surface liquid culture of Cordyceps militaris using highenergy ion beam irradiation. Lett. Appl. Microbiol. 47: 534-538.

Hansske, F. and M.J. Robins 1985. Regiospecific and stereoselective conversion of ribonucleosides to 3'-deoxynucleosides. A high yield three-stage synthesis of cordycepin from adenosine. Tetrahedron. Lett. 26: 4295-4298.

Jiang, X.L. and Y. Sun 1999. The determination of active components in various Cordyceps militaris strains. Acta. Edulia. Fungi. 6: 47-50.

Mao, X.B. and J.J. Zhong 2004. Hyperproduction of cordycepin by two-stage dissolved oxygen control in submerged cultivation of medicinal mushroom Cordyceps militaris in bioreactors. Biotechnol. Progr. 20: 1408-1413.

Mao, X.B. and J.J. Zhong 2006. Significant effect of $\mathrm{NH}_{4}{ }^{+}$on cordycepin production by submerged cultivation of medicinal mushroom Cordyceps militaris. Enzyme. Microb. Technol. 38:343-350.

Mao, X.B., T. Eksriwong, S. Chauvatcharin and J.J. Zhong 2005. Optimization of carbon source and carbon/nitrogen ratio for cordycepin production by submerged cultivation of medicinal mushroom Cordyceps militaris. Process. Biochem. 40: 1667-1672.

Masuda, M., E. Urabe, A. Sakurai and M. Sakakibara 2006. Production of cordycepin by surface culture using the medicinal mushroom Cordyceps militaris. Enzyme. Microb. Technol. 39: $641-646$.

Masuda, M., E. Urabe, H. Honda, A. Sakurai and M. Sakakibara 2007. Enhanced production of cordycepin by surface culture using the medicinal mushroom Cordyceps militaris. Enzyme. Microb. Technol. 40: 1199-1205.

Mizuno, T. 1999. Medicinal effects and utilization of 
S.K. Das, M. Masuda, M. Hatashita, A. Sakurai and M. Sakakibara / Our Nature (2009) 7:

$1-9$

Cordyceps (Fr.) link (Ascomycetes) and Isaria Fr. (Mitosporic fungi) Chinese Caterpillar fungi, "Tochukaso" (Review). Int. J. Med. Mushr. 1: 251-261.

Shih, I.L., KL. Tsai and C. Hsieh 2007. Effects of culture conditions on the mycelial growth and bioactive metabolite production in submerged culture of Cordyceps militaris. Biochem. Eng. J.
33: 193-201.

Song, C.H., Y.J. Jeon, B.K. Yang, K.S. Ra and J.M Sung 1988. Anti-complementary activity of exopolymers produced from submerged mycelial cultures of higher fungi with particular reference to Cordyceps militaris. J. Microbiol. Biotecnol. $8: 536-539$. 